\title{
ARTICLES \\ Using Breeding Technologies to Improve Farm Animal Welfare: What is the Ethical Relevance of Telos?
}

\author{
K. $\operatorname{Kramer}^{1}$ (D) F. L. B. Meijboom ${ }^{1}$ (D)
}

Accepted: 23 January 2021 / Published online: 9 February 2021

(c) The Author(s) 2021

\begin{abstract}
Some breeding technology applications are claimed to improve animal welfare: this includes potential applications of genomics and genome editing to improve animals' resistance to environmental stress, to genetically alter features which in current practice are changed invasively (e.g. by dehorning), or to reduce animals' capacity for suffering. Such applications challenge how breeding technologies are evaluated, which paradigmatically proceeds from a welfare perspective. Whether animal welfare will indeed improve may be unanswerable until proposed applications have been developed and tested sufficiently and until agreement is reached on how to conceptualize animal welfare. Moreover, even if breeding technologies do improve animal welfare, they might be objected to on other ethical grounds. Ethical perspectives on earlier animal biotechnologies are relevant for today's breeding technologies and their proposed applications, but may need reinterpretation. The current paper applies the concept of telos, which previously figured mainly in debates on classical genetic engineering, to genomic selection and genome editing aimed at improving animal welfare. It critiques current (Rollin's and Hauskeller's) accounts of telos and offers an alternative conceptualization that applies to recently proposed applications of breeding technologies. This account rejects both removing the desire to pursue characteristic activities and altering animal bodies in ways that compromise their ability to perform such activities, but conditionally allows increasing robustness against environmental stress. Our account of telos enriches ethical debate on these breeding technology applications by insisting on the connection between the good life, an animal's constitution, and its activities, thus countering reductive conceptions of welfare.
\end{abstract}

Keywords Telos $\cdot$ Genomics $\cdot$ Genome editing $\cdot$ Animal welfare $\cdot$ Ethics $\cdot$ Animal breeding

K. Kramer

k.kramer@uu.nl

1 Department of Population Health Sciences, Animals in Science and Society, Faculty of Veterinary Medicine, Utrecht University, Bolognalaan 50, 3584 CJ Utrecht, The Netherlands 


\section{Introduction: Applying New Breeding Technologies to Increase Animal Welfare and the Ethical Relevance of Telos}

Animal husbandry has been under ethical scrutiny for decades. At least since the publication of Animal Machines in 1964 (Harrison 2013), the welfare of animals involved in intensive production systems has taken center stage in the ethical awareness of various publics, even though this awareness is often played down psychologically (Onwezen and Van der Weele 2016). Some farming practices have changed as a result: for example, the use of veal crates and certain types of battery cages has been banned in some countries. The welfare of farm animals has also been linked to breeding practices, in particular to breeding efforts focusing narrowly on increasing yield (Sandøe et al. 1999), and this concern for animal welfare extends to responses to new breeding technologies. For example, some fear that genomic selection will speed up selective breeding for economically viable traits that affect welfare negatively (Coles et al. 2015); others stress the uncertain welfare effects of applying genome editing in livestock breeding (Schultz-Bergin 2018).

Breeding goals have developed over the years, however, and concern for animal health and welfare has been included in the concept of 'balanced' or 'responsible' breeding (EFFAB 2020), which led to the incorporation of health parameters in breeding decisions (Vosman et al. n.d.). Some further applications of breeding technologies to improve animal welfare are being debated. First, ethicists have been discussing the use of biotechnology to 'dumb down' or 'disenhance' animals - i.e. to breed animals with a decreased capacity to suffer under intensive farming conditions-since the 1980s (Rollin 1986), and some believe that gene editing will offer new possibilities for animal disenhancement (SchultzBergin 2017; Shriver and McConnachie 2018). While discussions on this issue have been partly speculative, some ethicists have addressed disenhancements that they considered technologically and biologically feasible. For example, an experimentally bred strain of blind chickens showed fewer signs of stress than their sighted counterparts in intensive production units, which prompted ethicists to consider whether breeding sightless chickens would be an acceptable way to improve animal welfare (Sandøe et al. 1999; Thompson 2008; Palmer 2011); others have reviewed scientific studies suggesting that the affective dimension of pain (how much an animal "minds" being in pain) could be diminished (Shriver 2009). Second, animals could be bred that lack features which are removed or changed physically in current agricultural practice. It is common practice, for example, to dehorn cows and trim the beaks of chickens, thus limiting the animals' ability to injure one another. The physical interventions involved are painful, though, and it has therefore been suggested that animal welfare could be improved by breeding hornless cows and chickens with blunt beaks (Croney et al. 2018; McConnachie et al. 2019; Van Eenennaam 2019; Streiffer and Basl 2011). Third, new breeding technologies could be applied to breed animals that are more resistant to environmental stressors, including heat, humidity, and infectious disease (Carabaño et al. 2017, Van Eennenaam 2019). For example, pigs resistant to African Swine Fever 
and to porcine reproductive and respiratory syndrome (PRRS) have been bred using genome editing (Lillico et al. 2016; Withworth et al. 2016), and genomic selection is used to increase mastitis resistance in dairy cows (Wiegel and Shook 2018). Although these applications of new breeding technologies have significant economic potential, it has also been argued that they serve animal welfare (e.g. Nuffield Council on Bioethics 2016).

That such applications of breeding technologies could improve animal welfare is a prima facie ethical argument in favor of their development and deployment. At the same time, approaching this issue from an animal welfare perspective faces definite limitations. First, it may be uncertain whether proposed applications of breeding technologies will indeed improve animal welfare until they have been sufficiently developed and tested. It may be unclear whether some application (e.g. some type of disenhancement) is biologically and practically feasible, for example, or whether negative welfare effects might surface. Biological models might for instance predict that editing pigs for improved resistance to African Swine Fever will not have negative side-effects for welfare, but this prediction must be premised on how precisely the edit will be performed and arguably calls for empirical confirmation. If so, an animal welfare perspective faces severe uncertainty when a breeding application is in an early stage of development and when the main question is whether it should be developed further. Editing animals in the research phase may well have negative welfare consequences for some of them. Second, proposed applications of breeding technologies may be premised on controversial conceptions of animal welfare: breeding hornless cows might for instance seem sensible if welfare is understood as the absence of pain but not if it requires species-typical behavior. Even if promoting animal welfare is widely accepted as a laudable goal, the enduring lack of agreement on how to conceptualize welfare complicates the ethical discussion on such breeding technology applications. Finally, even if breeding technologies can in fact enhance animal welfare, one may still question whether they ought to be used. Further ethical concerns regarding the use of breeding technologies have been raised, including concerns about the integrity and dignity of animals and concerns relating to their objectification and instrumentalization (e.g. Bovenkerk et al. 2002; Ortiz 2004; Hauskeller 2007). It cannot be assumed a priori that breeding technology applications that aim to improve welfare are immune to such concerns; indeed, such concepts have often been developed and invoked to articulate objections against supposedly welfare-enhancing interventions. Even more fundamentally, one may question whether biotechnological solutions to welfare problems in animal husbandry are appropriate at all. Some may regard the use of biotechnology as a 'technofix' that fails to address the underlying causes of welfare problems in animal husbandry; others may consider this use of biotechnology a non-ideal solution which is acceptable only as long as no radical revision of farming practices is forthcoming (cf. Shriver and McConnachie 2018).

These considerations call for a broader discussion on the ethical acceptability of using breeding technologies to improve animal welfare. From a responsible research and innovation (RRI) perspective, such a discussion is required if the application of breeding technologies for improved animal welfare is to be societally responsible (Bruce and Bruce 2019; Gremmen et al. 2019). 
The current paper focuses on the concept of telos and its relevance for the ethical evaluation of breeding technologies, in particular applications of genomics and genome editing that aim to breed animals with improved welfare. Telos is relevant here because it is often conceived as something that matters to animals but does not necessarily coincide with welfare (also depending on how welfare is conceptualized). Potential conflicts between animal welfare and telos have been discussed mainly for animal disenhancement by means of classical genetic engineering, but might perhaps also occur when breeding for improved welfare by other means. In addition, the concept of telos is believed to square with common sense moral concerns about animal breeding (Hauskeller 2005; Rollin 2014), which has been confirmed in qualitative empirical research (Macnaghten 2004). Considering what telos implies for proposed welfare applications of breeding technologies might thus help to anticipate and articulate the public's ethical views on this topic.

At the same time, the concept of telos is in need of clarification. It is not a standard term in people's ethical vocabularies and it can be understood variously, with different ethical implications. In critical discussion with older accounts of telos, which have been articulated primarily in debates on animal disenhancement using classical genetic engineering, the current paper offers a revised conceptualization of telos and applies it to proposed applications of contemporary breeding technologies to improve animal welfare (animal disenhancement, genetically removing features that will otherwise be altered by invasive physical interventions, and improving resistance to environmental stressors). Section 2 discusses Bernard Rollin's account, which defines an animal's telos as the set of the needs and interests that characterize an animal's 'basic nature' or 'form of life'. Rollin's conceptualization of telos is ultimately reductive: its ethical relevance depends entirely on its connection to animal welfare, understood as the satisfaction of needs and interests. It calls attention to the needs and interests that come with an animal's characteristic way of living and opposes breeding animals that lack capacities necessary to satisfy those interests, but it conditionally supports engineering animals so that they lack interests which cannot, or will not, be satisfied in the conditions for which they are bred (as well as increasing robustness against environmental stressors). This support for disenhancing animals has often been considered a counterintuitive implication of Rollin's reductive conceptualization. On Michael Hauskeller's account, which responds to Rollin's and is discussed in Sect. 3, an animal's telos comprises the ends towards which its bodily organization is directed. This account rejects breeding animals who do not desire these ends and cautions against using breeding technologies in ways that change or remove body parts. However, this account must be developed further if it is to be applied to breeding applications other than animal disenhancement, and its ethical relevance depends on the controversial intuition that what animals' bodies are directed at must therefore be considered good. Building on these accounts and inspired by an ambiguity in Aristotle's philosophy, Sect. 4 proposes an account that equates telos with the set of good activities that members of a species characteristically pursue and are well-equipped to perform. This account is critical of removing the desire to pursue activities characteristic of the species and altering animal bodies in ways that compromise their ability to perform these activities well, but may allow increasing robustness against environmental stressors. We argue that 
while our understanding of telos is committed to the claim that performing certain activities is good in itself and ascribes an internal teleology to animals, it can be paired with both objective and subjective accounts of animal welfare and fits into the debate concerning the agency of ('higher') animals. The ethical relevance of this account is that it counters reductive conceptions of animal welfare by insisting on the interconnection between welfare, an animal's activities, and its bodily constitution. We believe that this offers a rich and defensible ontological picture that may help to broaden the debate.

\section{Bernard Rollin's Account of Telos and Its Implications for Using Breeding Technologies to Improve Animal Welfare}

The concept of telos gained attention in animal ethics in the 1980's through the work of Bernard Rollin, who regularly discussed the concept in relation to genetic engineering (E.g. Rollin 1986, 1998, 2014). Rollin defines an animal's telos as:

The set of needs and interests which are genetically based, and environmentally expressed, and which collectively constitute or define the 'form of life' or way of living exhibited by that animal, and whose fulfillment or thwarting matter to the animal ... the telos of an animal will tend to be a characterization of the basic nature of a species (Rollin 1998: 162).

Telos is thus related to the "form of life" or "basic nature" of the animal, and this is to be understood as the "pigness of the pig" or the "dogness of the dog" (Rollin 2014: 106). It concerns how animals of this species perform the functions any living being performs in some way: sensation, nutrition, locomotion, growth, and reproduction (Rollin 1998: 157; 2014: 100). Sayings like "fish gotta swim, birds gotta fly" show that common sense acknowledges the importance of living according to telos (Rollin 1986: 88; 2014: 100). Telos not only characterizes what it means to be an animal of some species, but also explains what things "matter" to animals of that species. Living according to its basic nature or form of life means that an animal lives a good life for a pig, a dog, or whatever species it is a member of and therefore clearly matters to it (E.g. Rollin 1998: 165; 2014: 106). Telos thus helps to explain what an animal needs in order to do well, considering which species it is a member of, and hence translates into a species-relative set of "needs and interests". For example, the idea of telos suggests that the lives of farmed pigs should be evaluated in terms of the extent to which they can exhibit the way of living that is characteristic for pigs. If there is a discrepancy between that characteristic way of living and how an animal can actually behave, which arguably is often the case in intensive farming systems, that animal is not living a good life for an animal of its species (Rollin 1998: 159; 2014: 104-105).

Telos is also crucial in Rollin's ethical evaluations of breeding technologies, which he bases on the principle of conservation of welfare. According to this principle, changing animals genetically is wrong if the change leads to diminished welfare, right if it leads to increased welfare, and neutral if welfare is unaffected (Rollin 1998: 169; 2014: 110). Combined with Rollin's understanding of welfare as the 
satisfaction of the needs and interests that define an animal's telos, this principle rules out applications of breeding technologies that compromise an animal's ability to realize its telos. Breeding cows that grow more meat tissue is unethical, for example, if these animals face additional difficulties in satisfying the needs and interests that characterize a cow's life (Rollin 1986: 89). It is presupposed in such cases that the animal's telos is unaffected by the genetic change. However, Rollin's contention that telos is genetically based implies that an animal's telos can in principle be changed by altering its genetic make-up. Selective breeding has already changed the teloi of farm animals - the selection of animals that were easier to handle has for example led to more docile animals (Rollin 2014: 102, 108) — and genetic engineering might open up further ways to alter animals' teloi. Rollin argues that changing an animal's telos can be justified by the principle of conservation of welfare. More specifically, it would be ethically right to remove needs and interests that farm animals cannot satisfy given current farming practices. Such animals would have fewer unmet needs and interests and thus, given Rollin's understanding of welfare as the extent to which an animal's needs and interests are met, a higher level of welfare. Unless farm animals' living conditions can and will be changed so they can fulfil their needs and interests, we ought to change farm animals so they have fewer needs and interests that they cannot fulfil (Rollin 1998: 167ff; 2014: 108ff).

Rollin's account of telos thus has clear implications for the use of breeding technologies to 'disenhance' or 'dumb down' animals by decreasing their capacity to suffer. It conditionally supports this use of breeding technologies, but insists that more is required than removing negative experiences. Rollin posits that animals that cannot satisfy the needs and interests that comprise their telos have poor welfare even if negative experiences are absent. A pig solitarily confined in a small space, for instance, cannot meet its interest in performing characteristic and genetically based pig-activities, and is therefore not living a good pig's life regardless of whether it experiences its state negatively. Neither is the problem that the pig is deprived of positive experiences. Rollin objects to understanding the good for animals merely in terms of subjective experiences, and construes his account of telos as an alternative to hedonistic conceptualizations of welfare (Rollin 2014: 105). Therefore, on our interpretation of Rollin, the problem of having unmet needs and interests is not just that this results in having negative experiences or lacking positive ones. Unmet needs and interests instead have a direct negative impact on welfare, an impact that is logically independent from having negative or lacking positive experiences. This is in our view what allows Rollin to consistently argue against removing negative experiences-which might in principle include removing negative experiences associated with having unfulfilled needs and interests_-and for removing unmet needs and interests. Moreover, Rollin sees no necessary connection between an animal's needs and interests and its bodily constitution, as Hauskeller (2005) objects. This suggests that needs and interests could in principle be removed genetically without changing the animal's bodily constitution and that needs and interests are internal states of animals.

By contrast, Rollin's account would not support removing physical features from animals to improve animal welfare, including features that in current agricultural practice are removed or changed through painful interventions. Unless 
Rollin means (contrary to our interpretation in the previous paragraph) that an animal's needs and interests follow from its genetically determined physical features, and are thus only based on genetics in an indirect sense, removing those physical features by genetic engineering may not remove the associated needs or interests. For example, chickens bred with blunt beaks might still have an interest in engaging in pecking behaviors that require a sharp beak. If so, the physical change deprives the animal of the means to meet its needs and interests. Bringing about this change through genetic intervention rather than mechanical debeaking may help to avoid pain, which would be desirable from a hedonistic perspective, but still leaves a large welfare problem on Rollin's account. If chickens become unable to meet their needs and interests either way, the genetic alteration also has negative welfare implications and is barely an improvement over mechanical debeaking.

Finally, Rollin's account would arguably regard increasing robustness against environmental stressors such as infectious disease neutrally or even positively. Increasing an animal's disease resistance does not necessarily seem to limit the extent to which it can meet the needs and interests that define its form of life; if anything, increased disease resistance might prevent that the animal's attempts to satisfy its needs and interests are thwarted by disease. (This seems to presuppose, though, that the animal can satisfy its needs and interests if it does remain healthy, which according to Rollin does not apply in intensive farming conditions.) The same reasoning applies to increasing robustness against other types of environmental stressors.

Rollin conceptualized welfare in terms of needs and interests primarily in response to hedonistic conceptions of welfare (Rollin 2014: 105-106). He thereby broadened the debate on breeding technologies: he challenged evaluating breeding technology applications solely in terms of positive and negative effects on the animal's subjective experiences and offered evaluating them in terms of their effects on needs and interests as an alternative. Moreover, by grounding an animal's needs and interests in its "basic nature" or "form of life", his concept of telos offers a useful heuristic for identifying needs and interests that matter to it. Ultimately, however, the ethical relevance of telos is reducible to its relevance for welfare. Not respecting telos is an ethical problem according to Rollin because of its negative implications for welfare (understood in terms of the non-satisfaction of needs and interests), and his principle of conservation of welfare allows changing an animal's telos if doing so is neutral or beneficial for welfare. However, some have objected to this reductive conceptualization of telos and its implication that disenhancing animals is conditionally acceptable. While we agree with Rollin that animals who have needs and interests that cannot or will not be met are (other things being equal) worse off than animals who lack such needs and interests, which is a prima facie reason to disenhance animals bred for certain unfavourable living conditions, we agree with his critics that what matters to an animal cannot be reduced to the satisfaction of needs and interests. One critic who has offered a broader conceptualization of telos and used it to articulate what matters to an animal is Michael Hauskeller's, to whose critique and alternative we now turn. 


\section{Michael Hauskeller's Account of Telos and Its Implications for Using Breeding Technologies to Improve Animal Welfare}

Michael Hauskeller criticizes Rollin for deflating the concern for telos into a concern for animals' actual needs and interests: although Rollin's conception of telos helps to identify sources of animal suffering, Rollin stripped the term from its Aristotelean implications by not understanding it in terms of what needs and interests an animal should have (Hauskeller 2005: 64). Telos ought to be resituated in a properly Aristotelean conceptual framework if its application to the genetic engineering of animals is to be adequate.

For Aristotle, according to Hauskeller, telos is the end for the sake of which an animal is (or comes to be) what it is, namely performing those actions which are natural to it, "the full and active life characteristic of its kind" (2005: 69). This end is internal to the animal: it is what animals direct and build themselves towards, for their own sake. Hauskeller draws special attention to the interrelation between the telos of an animal and its bodily organization. He argues that for Aristotle, an animal's body is entirely directed at the kind of life that constitutes its end or telos: that an animal has the bodily constitution it does must be explained by the kind of activities that constitute its telos (ibid.: 67). Conversely, an animal's bodily constitution indicates the kind of life which it is directed at, which it is in that sense 'meant' to live, and which must be considered its good (ibid.: 69).

Hauskeller (ibid.: 71-72) draws on this connection between telos and bodily organization to answer the objection that telos presupposes that species are unchangeable natural kinds, which would be at odds with contemporary biology. He argues that species' changing over time does not refute the idea that animals have a telos: even if a species does not have a fixed nature that would determine the telos of its members, individuals still have a physical constitution that is directed at certain ends (e.g. flying or swimming), and those ends comprise its telos. Aristotle, according to Hauskeller, already understood telos in this individualized way. The Aristotelean idea of telos is about "what this particular chicken is, towards which end it is directed, and what, in consequence, its own particular good is" (ibid.: 72). It is nevertheless possible to speak of the telos of, for example, chickens, because chickens as we know them are typically physically constituted to perform certain activities.

Connecting telos to bodily organization also enables Hauskeller to articulate an objection against dumbing down or disenhancing animals by removing urges and desires. For example, it supports the intuition that:

[I]t is sad to see a tiger confined to a small cage when we have the impression that he would much prefer to roam in the wild, but it might be considered even sadder to see it there and have the impression that he does not even mind anymore, and is for all we know content with his lot (ibid.: 72-73).

The tiger's body shows what kind of life tigers should be directed at, and this makes a tiger who is content in captivity a 'sad' view. Hauskeller's explanation 
of why this is sad is that the tiger's bodily organization still shows which activities constitute the good life for a tiger. We do not think a tiger that does not desire freedom is doing well, even though it has no unpleasant experiences because of its captivity, because it is not leading the right kind of life for a creature with its bodily constitution (ibid.: 72-73).

Hauskeller furthermore explores the relations between an animal's telos and the function of its body parts (ibid.: 67-69). He argues that for Aristotle, an animal's body parts cannot be understood properly without reference to their function or purpose in the body as a whole, which must in turn be understood with reference to the characteristic activities of an animal of its species. For instance, a zebrafish's fins should be understood as a necessary part of the body if zebrafish are to swim, and swimming should be understood as a part of what it means to be a zebrafish. Hauskeller insists on the body's "intricate organization, the subtle interaction of its parts" here (ibid.: 68). He explains that:

Aristotle's whole point was that the organism is just that: an organism. This means that it needs this particular trait in order to be complete, because no organ is what is independent of the others and independent of the purposes it is meant to serve (ibid.: 72).

Accordingly, Hauskeller states, "removing or transferring a few genes in order to get rid of a particular trait" (ibid.: 72) does not change the organism's telos; other parts of the organism's bodily organization will still be directed at the activities that constitute its telos.

This part of Hauskeller's account seems relevant when evaluating breeding technology applications that aim to alter physical features that are currently changed by invasive procedures. By calling attention to the complex contributions of an animal's traits in its functioning as a whole, Hauskeller opposes understanding body parts reductively as isolable physical features or considering only their relevance for vital functions. Disrupting the functioning of a body part (for example when breeding boars the testes of which do not mature) means that the body will be directed at activities that the animal cannot perform properly. If only for the continued presence of the body part, the body is still directed at those activities as part of its telos. When genetically removing body parts, furthermore, animals may be unable to employ activities that their bodily organization is still directed at in other ways and that are still part of their telos. For example, the muscular physique of a hornless bull arguably still indicates the activities by which bulls determine their place within a social hierarchy and which horns help to perform. However, Hauskeller mainly addresses the use of genetic engineering to 'dumb down' animals and does not explicitly consider the implications of his account for breeding technology applications that could replace invasive physical procedures. Hauskeller's insistence on the complexity of an animal's telos and its relation to bodily constitution seems important, but his account requires further development if it is to be applied to the genetic removal of body parts such as cows' horns or the alteration of body parts such as chickens' beaks.

Most importantly, Hauskeller does not clarify whether an animal's telos can be changed at all by changing its physique genetically. If removing or altering a 
body part does not change an animal's telos because its bodily constitution continues to refer to its characteristic activities, could its telos be changed by changing its body more radically? Hauskeller's account does require considering a physical feature's integration with other traits, but what if interdependent traits are changed or removed simultaneously? Moreover, some activities (e.g. pecking) may involve only few necessary features (e.g. a sharp beak); it is unclear how the body of an animal from which such features are removed still indicates those activities. It is hence unclear why the animal's telos would remain unaltered.

The possible application of animal breeding techniques to change or remove physical features, in particular features that are routinely altered by invasive procedures in current agricultural practice, thus raises questions that Hauskeller does not address. The same goes for the application of such techniques to breed animals which are more robust against environmental stressors. There seems to be no necessary connection between increasing robustness and removing animals' desires or altering their bodies in ways that disrupt the "intricate organization, the subtle interaction of [their] parts" (ibid.: 68). Moreover, keeping an animal in good shape in spite of environmental challenges such as infectious disease means that it can remain engaged in the activities towards which its body is directed. If anything, Hauskeller's account would therefore seem to support increasing farm animals' robustness against environmental stressors (again provided that robust farm animals can do what their bodies are directed at).

Hauskeller's account opens up new perspectives on the use of breeding technologies to improve animal welfare. It rejects understanding the animal's good in terms of subjective experiences or in terms of the satisfaction of its actual needs and interests, and instead insists that an animal's good includes performing activities to which its bodily constitution is directed. The body and its purpose should thus be taken into account when evaluating breeding technology applications. This challenges potential applications that would remove needs and desires that animals cannot meet under the conditions for which they are bred, at least insofar as their bodies remain directed at fulfilling those needs and desires. In addition, by insisting on the complex dependencies between an animal's physical features, Hauskeller's account cautions against genetically adapting animal bodies in ways that might compromise their ability to perform activities to which their bodies refer.

We believe that Hauskeller's account of telos can help to resist reductive conceptualizations of animal welfare that would dissociate the animal's good from its activities and its bodily constitution. It offers a rich ontology for thinking about what matters to animals that can broaden the debate on the use of breeding technologies. However, we take issue with one central part of Hauskeller's account. More specifically, why should the activities towards which an animal's body is directed be considered good? Hauskeller's answer is to insist on the supposedly Aristotelean intuition that "whatever it is "for the sake of which" all the parts that make up a particular organism are made and conjoined, must be good", which according to Hauskeller is "as plausible as it is possible for any intuition about what is good, or bad" (ibid.: 73, original emphasis). He concedes that 'good' could be understood here merely as what is good for animals and that it does not logically follow that what is good for animals is therefore morally relevant; the need to respect their good 
is not a logical entailment but entirely a moral need. Be that as it may, the intuition that what animals are aimed at must be considered good and should be respected is probably not shared widely today, and those who reject it can consistently reject Hauskeller's reasoning that animals should not be changed in ways that make them unwilling or unable to pursue activities that their bodily constitution is directed at. We think that the relation between the good and what animals are directed at can be accounted for in an intuitively more plausible way, however. This leads to a different account of telos, which has some different implications for the use of breeding technologies to improve animal welfare than Rollin's and Hauskeller's accounts. We present that account in the following section.

\section{A Third Account of Telos and Its Implications for Using Breeding Technologies to Improve Animal Welfare}

Hauskeller's conceptualization of telos thus opens up further ethical perspectives on breeding technology applications, but its ethical relevance rests on the controversial intuition that the activities towards which an animal's body is directed must therefore be considered good. Hauskeller apparently considers this a necessary intuition on a properly Aristotelean account of telos, but Aristotle himself seems to have been ambiguous about the relation between the activities that constitute a being's telos and its good. As Veatch (1981) has pointed out, this ambiguity can be expressed as a dilemma that is similar to Plato's Euthyphro dilemma. Plato asks whether the pious is pious because it is loved by the gods, or whether the pious is loved by the gods because it is pious; similarly, one may ask whether the good is good because it is aimed at, or whether it is aimed at because it is good. Hauskeller insists that what is aimed at must therefore be considered good and thus grasps the first horn of this dilemma. This seems to be supported by the beginning of the Nicomachean Ethics (' $N E$ ', e.g. Aristotle 1980). Here, Aristotle famously states that

Every art and every inquiry, and similarly every action and pursuit, is thought to aim at some good; and for this reason the good has rightly been declared to be that at which all things aim (NE I.1).

This passage is often interpreted as defining the good as that at which all things aim, which strongly suggests that the good is good because it is aimed at. This interpretation implies that the good is thoroughly species-relative: animals of different species aim at different things, which is sufficient to make different things good for them.

However, Aristotle also seems to recognize a sense in which the good is not species-relative. The clearest indication for this is perhaps in the Nicomachean Ethics book X chapters 7 and 8 . Here, Aristotle says that gods are believed to be more blessed and happy than humans, who are in turn more happy than animals. Aristotle explains that gods are the most blessed because their entire activity consists in theoretical contemplation, whereas humans can engage in theoretical contemplation only to some extent, and animals not at all. Practical contemplation is also worthwhile, however, and even a life of pleasure can have some value (e.g. NE X.1-3). Although Aristotle insists that different species are directed at different activities, 
he thus proposes a hierarchy of good activities that crosses species. Aristotle seems to distinguish here between the good life for a member of a species and the good life full stop (Thorsrud 2015): while Aristotle's hierarchical order of good activities transcends species, the good life for a member of a species takes into account which good activities members of that species (can) actually engage in.

How these different senses of 'the good life' can be reconciled has occupied various commentators, and we do not claim to resolve this issue. However, we do think that this ambiguity allows exploring an account of telos that grasps the second horn of the Euthyphro-style dilemma. The point is not exegetic: we do not aim to offer the interpretation of telos that is most firmly anchored in Aristotle's works. Rather, the point is to develop an account that has significant ethical implications for the use of breeding technologies to improve animal welfare, that replaces the controversial intuition on which the ethical significance of Hauskeller's conceptualization rests, and that yet respects (a plausible interpretation of) the Aristotelean framework from which the term originates to a sufficient degree.

Grasping the second horn of dilemma, our account thus holds that animals aim at the good because it is good. Following Aristotle, this good is the good life, which consists in performing (some blend of) good activities (e.g. EN I.7-8). These activities must not merely be performed but must be performed well: a human that engages in theoretical contemplation but makes all kinds of errors does not seem to be flourishing, and neither does a tiger that hunts but is too clumsy to catch prey, even if it were somehow provided with adequate food. This point also connects the good life for a member of a species to the good life full stop. Even if certain activities are good absolutely, a good life for a member of a species must consist in performing activities that it is equipped to perform well. Aiming at goods that one is poorly equipped to pursue is doomed to fail. A human that tries to live like a god by devoting himself entirely to theoretical contemplation, without regard for the limitations implied by his embodiment and social nature, will attain neither the good life for a god nor that for a human (EN X.7-8); a rhesus macaque that is trained to perform characteristic human behaviors will probably do poorly both as a human and as a rhesus macaque. This account can thus maintain both that certain activities are good absolutely and that the good life is species-relative: how members of a species are (typically) constituted or equipped determines which good activities they can (typically) perform well. There may be something inherently good in suckling young, for example, but zebrafish and chickens are just not equipped for this good.

These considerations lead us to define telos as the set of good activities that members of a species typically pursue and are equipped to perform well. As just explained, our account posits that certain activities are good absolutely, but only if they are performed well, which means that good activities that members of a species are poorly equipped to perform cannot be part of their telos. The definition also posits that members of a species typically pursue those good activities for which they are well-equipped. This is to be interpreted as ascribing an internal teleology to creatures such as animals: animals direct themselves at good activities, and they do so because these activities are good (cf. Harfeld 2013; Grumett 2019). Moreover, this is an internal teleology that tends to respect the animal's constitution-animals typically do not pursue activities for which they are poorly constituted. Telos is 
defined as a set of good activities because animals typically pursue various activities and because flourishing on an Aristotelean view requires as much (cf. Nussbaum 2006).

While we have been referring to the good life for members of a species, our account does not have to assume that species are unchangeable natural kinds, as Aristotle's account did. Our point that the good of members of a species depends on what inherently good activities they are well-equipped to perform is not meant to deny that some members of a species will be better equipped for certain activities than others, or that the set of activities for which members of a species are generally well-equipped changes over time. Some animals may be better equipped for certain activities than many of their conspecifics due to natural variation; some particular chimpanzees or grey parrots might for example be exceptionally talented for learning to communicate through human languages. Alternatively, individual animals may acquire uncommon characteristics by human invention (e.g. through genome editing or by crossing animals that normally would not mate). In any such cases, whether these animals have a good life does not depend directly on the extent to which their activities conform to how their conspecifics (or members of the species they descend from) generally behave; whether individual animals behave or do not behave as members of their species typically do is not what makes their activities good or bad. Rather, what determines whether these animals have good lives is whether they can engage in a rich and well-balanced set of good activities. Looking at the set of activities that members of a species typically engage in successfully, when they are given the chance, is in our view a shorthand for identifying a set of activities that it would be worthwhile for individuals to engage in and that they could normally pursue successfully. It is conceivable that animals pursuing a different mix of good activities than most of their conspecifics still achieve a good life. However, on our conception of telos, they would have to engage in a sufficiently rich mix of activities and perform each of these activities well. As we argue later, humans' limited abilities to appreciate the good (if any) in many animal activities creates a presumption not to change animals' set of typical behaviours.

Our definition of telos can be connected to Rollin's by equating activities that members of a species typically pursue to their 'form of life' or 'basic nature'. In contrast to Rollin's, however, this account does not consider activities good insofar as performing them satisfies animal's actual (genetically based) needs and interests; animals instead have an interest in performing good activities because these activities are good in themselves. It can be connected to Hauskeller's view by agreeing on the importance of bodily constitution. A main difference however is that activities are not considered good because animal bodies are directed towards them; bodily constitution instead determines which inherently good activities animals are equipped to perform. The current account replaces Hauskeller's intuition that what an animal's body is directed at must be considered good by the intuition that performing certain activities well is inherently good for an animal, where an animal's body indicates which good activities it can engage in successfully.

Applying this account to the use of breeding technologies to enhance animal welfare, it would not support disenhancing animals by removing the desire to engage in characteristic activities. If being engaged in such activities is good and animals 
are capable of performing these activities well, lacking the desire to perform them must be considered bad. Genetic disenhancement might target urges to pursue activities that animals cannot successfully engage in under the conditions for which they are bred, in which case removing those urges does not impair their lives further but does not improve their lives either. Disenhanced animals then just fail to engage in activities that make up a good life for a different reason than their unaltered counterparts: they will not pursue some inherently good activities that they are physically equipped to perform. Although the lives of the disenhanced animals may be better from a hedonistic or desire-satisfaction welfare perspective, as they lack unfulfilled desires and correspondingly have fewer frustrations, they are not doing any better on our telos perspective.

This account would also caution against using breeding technologies to remove or change physical features. The good life does not merely require the pursuit of some set of good activities, but also requires that those activities are performed well. An animal's bodily constitution determines which activities it is can perform successfully, and changing it physically therefore risks limiting the animal's ability to engage in activities that comprise a good life. For example, if the horns of cows, the beaks of chickens or the tails of pigs are implicated in inherently good activities that these animals characteristically perform (e.g. in types of communication that are socially important), removing these features by genetic intervention leaves their lives impoverished.

Evaluating breeding technology applications by considering whether they might impair animals' desire or ability to engage in certain typical activities suggests that adapting animals to increase their robustness against environmental stressors is not intrinsically objectionable. If anything, environmental stressors such as infectious pathogens threaten to limit animals' desire and ability to pursue good activities, and increasing their robustness might thus help animals to realize their telos. This again assumes that animals will successfully pursue good activities if they can resist environmental stressors, which may depend on their living conditions, and it assumes that an animal's desires and abilities to engage in these activities are in no way impaired in the process of increasing their robustness.

The defining commitments of our conceptualization of telos include the assumption that performing certain activities well is inherently good and the assumption that animals pursue certain activities that they are well-equipped to perform because these activities are good. These assumptions allow our account of telos to relate an animal's good to its activities and to its constitution, while avoiding Hauskeller's controversial intuition that certain activities are good for animals because they are directed at them. The moral ontology that our account of telos thereby presents can serve to broaden the debate on the use of breeding technologies to improve animal welfare. Yet these defining assumptions may attract objections of their own, to which we now turn. We do not aim to rebut these objections here, but use them to show how our conception of telos fits into wider debates.

First, the assumption that performing certain activities well is inherently good may be controversial. Note, however, that the inherent goodness of performing certain activities can still be unpacked in several ways. These activities might be construed as items on a (species-relative) 'list' that defines welfare objectively, for 
example, or one might posit that performing those activities involves good experiences that have a sui generis phenomenological quality. In either case, however, our conceptualization of telos insists that the animal's good is inseparable from its activities and its bodily constitution. It also fits well with accounts that define animal welfare in terms of species-typical functioning. Telos can explain why species-typical functioning is important for animal welfare: species-typical functioning covers those inherently good activities that members of a species typically and successfully engage in. This explanation has distinctive implications for the use of breeding technology to improve animal welfare. Because species-typical activities are also assumed to be good in a non-relative sense, limiting animals' urge or ability to engage in species-typical behavior can be considered bad for them, even if one might justifiably say that the species' characteristic behavior is changed simultaneously. If so, there is a presumption not to change typical species-typical behaviors. We humans may not fully understand what is good in activities like dust bathing or rooting, but we cannot conclude that there is no good in performing those activities-we simply may not appreciate what it is like to be a chicken or a pig (cf. Nagel 1974), for example. In conclusion, the assumption that performing certain activities is inherently good connects to various conceptualizations of animal welfare, but our account of telos arguably enriches the debate on animal welfare by insisting on the interrelation between an animal's good, its activities and its bodily constitution.

Second, it may be controversial to ascribe animals an internal teleology by which they are directed at inherently good activities. The ascription of an internal teleology to animals does not mean that every activity pursued is good (animals may for example err in what they perceive to be good), only that characteristic activities generally are. Still, this assumption seems to assign animals with agency or even a kind of autonomy that involves shaping one's life according to some conception of the good (cf. Harfeld 2013; Grumett 2019). What kind of agency, if any, should be assigned to animals is subject of a debate involving various academic disciplines (e.g. McFarland and Hediger 2009; Rowland 2013). Our account of telos may thus broaden the debate on the welfare applications of breeding technologies by connecting to the debate on animal agency.

Third, and relatedly, although we have followed Hauskeller in emphasizing the importance of bodily constitution for telos, we did not mean to deny that cognitive abilities also crucially determine the range of activities which animals can successfully engage in. Thus, our discussion of telos connects to debates on what cognitive abilities animals have because these abilities co-determine what activities can be part of the good life for these animals.

\section{Conclusion}

In this paper, we conceptualized telos as the set of good activities that members of a species typically pursue and are equipped to perform well. This conceptualization of telos arguably broadens the debate on supposedly welfare-enhancing applications of breeding technologies. It does so by challenging reductive welfare conceptions: it insists that what matters to an animal cannot be dissociated from its characteristic 
activities and its bodily constitution. As a result, our account of telos has particular implications for using breeding technologies to improve animal welfare. It supports neither disenhancing animals by removing urges to engage in activities that they cannot perform under farming conditions nor genetically altering physical features that are currently altered by invasive physical interventions (at least insofar as these features are required for characteristic activities). The concept of telos thus challenges the justification for developing and deploying these breeding technology applications, which is premised on too narrow a construal of what matters to animals, and which therefore fails to address the real plight of animals under some farming conditions: that they cannot engage in those activities that make up a good life and which fit their constitution. It does allow increasing animals' robustness against environmental stressors such as infectious disease, humidity, and heat, assuming that their increased robustness does not diminish their urge or ability to engage in good activities. Thus, if telos were to be accepted as an important ethical concern, approaching welfare problems in animal farming through the breeding technology applications we have discussed would prove to be largely wrongheaded, although applications aimed at increasing robustness against environmental stressors might not. Accordingly, some shifts of direction would have to be made in scientific inquiry aimed at improving the welfare of farmed animals, and it appears that some welfare problems of animal husbandry cannot be addressed adequately by biotechnological means at all; this applies in particular to problems stemming from the inability to engage in a sufficiently rich set of good activities that match the animals' abilities. Even if applying breeding technologies proved to be the only viable response to such problems, given the difficulty of actually changing farming practices, the concept of telos would point to the significant moral problems that would remain.

Obviously, this conceptualization of telos also has limitations. While it offers a broader picture of what matters to an animal, further ethical considerations may be relevant for the evaluation of breeding technology applications. For example, even though telos seems to support increasing animals' robustness against infectious disease and other environmental challenges, other animal ethical concepts might not. Ethical concepts such as animal dignity, integrity, and instrumentalization also merit consideration. Moreover, we do not claim that concern for telos necessarily overrides concern for subjective (e.g. hedonistic) welfare; we do not exclude that compromising telos to improve subjective welfare can be ultima facie acceptable if it proves impossible to enable farm animals to live more according to telos. The current paper is but a partial attempt to open up debate on contemporary welfare applications of breeding technologies by calling for the inclusion of further ethical concepts. This attempt to open up debate should also frame objections to our conceptualization of telos, such as the objections discussed at the end of the previous section. While we have argued for our conceptualization of telos by highlighting some advantages over Rollin's and Hauskeller's accounts, we do not claim to have refuted their accounts or to have offered the definitive interpretation of telos. Rather, we claim that the concept of telos can be unpacked in plausible ways and has significant ethical implications. We therefore press for its inclusion and discussion in debates on the use of breeding technologies to improve animal welfare. 
Funding This research was made possible by funding from the Dutch Research Council (Grant Number 313-99-331) and from the European Union (Grant Agreement: 815668).

\section{Compliance with Ethical Standards}

Conflict of interest KK reports having no conflicting interests. FLBM reports having no conflicting interests.

Open Access This article is licensed under a Creative Commons Attribution 4.0 International License, which permits use, sharing, adaptation, distribution and reproduction in any medium or format, as long as you give appropriate credit to the original author(s) and the source, provide a link to the Creative Commons licence, and indicate if changes were made. The images or other third party material in this article are included in the article's Creative Commons licence, unless indicated otherwise in a credit line to the material. If material is not included in the article's Creative Commons licence and your intended use is not permitted by statutory regulation or exceeds the permitted use, you will need to obtain permission directly from the copyright holder. To view a copy of this licence, visit http://creativecommons.org/licen ses/by/4.0\%.

\section{References}

Aristotle. (1980). The Nicomachean ethics, translated by Ross D. Oxford: Oxford University Press.

Bovenkerk, B., Brom, F. W. A., \& Van den Bergh, B. J. (2002). Brave new birds: The use of "animal integrity" in animal ethics. The Hastings Center Report, 32, 16-22.

Bruce, A., \& Bruce, D. (2019). Genome editing and responsible innovation, can they be reconciled? Journal of Agricultural and Environmental Ethics, 32, 769-788.

Carabaño, M. J., Ramón, M., Díaz, C., et al. (2017). Breeding for resilience to heat stress effects in dairy ruminants. A comprehensive review. Journal of Animal Science, 95, 1813-1826.

Coles, D., Frewer, L. J., \& Goddard, E. (2015). Ethical issues and potential stakeholder priorities associated with the application of genomic technologies applied to animal production systems. Journal of Agricultural and Environmental Ethics, 28, 231-253.

Croney, C., Muir, W., Ni, J.-Q., et al. (2018). An overview of engineering approaches to improving agricultural animal welfare. Journal of Agricultural and Environmental Ethics, 31, 143-159.

EFFAB (2020) Code EFABAR. https://www.responsiblebreeding.eu/. Accessed 15 July 2020

Vosman JJ, Van Pelt ML, De Jong G (n.d.) Genetic parameters for health traits using farmer recorded data in the Netherlands and Flanders. Coöperatie CRV. https://www.cooperatie-crv.nl/wp-content/uploa ds/2019/02/Farmer-recorded-data_Vosman.pdf

Gremmen, B., Blok, V., \& Bovenkerk, B. (2019). Responsible innovation for life: Five challenges agriculture offers for responsible innovation in agriculture and food, and the necessity of an ethics of innovation. Journal of Agricultural and Environmental Ethics, 32, 673-679.

Grumett, D. (2019). Aristotle's ethics and farm animal welfare. Journal of Agricultural and Environmental Ethics, 32, 321-333.

Harfeld, J. L. (2013). Telos and the ethics of animal farming. Journal of Agricultural and Environmental Ethics, 26, 691-709.

Harrison R (2013 [1964]) Animal machines. CABI, Wallingfort

Hauskeller, M. (2005). Telos: The revival of an Aristotelian concept in present day ethics. Inquiry, 48, $62-75$.

Hauskeller, M. (2007). The reification of life. Genomics, Society and Policy, 3, 70-81.

Lillico, S. G., Proudfoot, C., King, T. J., et al. (2016). Mammalian interspecies substitution of immune modulatory alleles by genome editing. Scientific Reports. https://doi.org/10.1038/srep21645.

Macnaghten, P. (2004). Animals in their nature: a case study on public attitudes to animals, genetic modification and 'nature.' Sociology, 38, 533-551.

McConnachie, E., Hötzel, M. J., Robbins, J. A., et al. (2019). Public attitudes towards genetically modified polled cattle. PLOS ONE, 14, e0216542. https://doi.org/10.1371/journal.pone.0216542. 
McFarland, S. E., \& Hediger, R. (Eds.). (2009). Animals and agency: an interdisciplinary exploration. Leiden: Brill.

Nagel, T. (1974). What is it like to be a bat? Philosophical Review, 83, 435-450.

Nuffield Council on Bioethics (2016) Genome editing: an ethical review. https://www.nuffieldbioethi cs.org/publications/genome-editing-an-ethical-review. Accessed 15 July 2020

Nussbaum, M. C. (2006). Frontiers of justice: Disability, nationality, species membership. Massachusetts: The Belknap Press of Harvard University Press.

Onwezen, M. C., \& Van der Weele, C. N. (2016). When indifference is ambivalence: Strategic ignorance about meat consumption. Food Quality and Preference, 52, 96-105.

Ortiz, S. E. G. (2004). Beyond welfare: Animal integrity, animal dignity, and genetic engineering. Ethics and the Environment, 9, 94-120.

Palmer, C. (2011). Animal disenhancement and the non-identity problem: A response to Thompson. Nanoethics, 5, 43-48.

Rollin, B. E. (1986). On telos and genetic manipulation. Between the species 2, https://doi.org/10.15368 /bts.1986v2n2.9.

Rollin, B. E. (1998). On telos and genetic engineering. In A. Holland \& A. Johnson (Eds.), Animal biotechnology and ethics (pp. 156-171). Dordrecht: Springer.

Rollin, B. E. (2014). Telos, conservation of welfare, and ethical issues in genetic engineering of animals. In G. Lee, J. Illes, \& F. Ohl (Eds.), Ethical issues in behavioral neuroscience (pp. 99-116). Heidelberg: Springer.

Rowland, M. (2013). Can animals be moral? New York: Oxford University Press.

Sandøe, P., Nielsen, B. L., Christensen, L. G., \& Sørensen, P. (1999). Staying good while playing GodThe ethics of breeding farm animals. Animal Welfare, 8, 313-328.

Schultz-Bergin, M. (2017). The dignity of diminished animals: species norms and engineering to improve welfare. Ethical Theory and Moral Practice, 20, 843-856.

Schultz-Bergin, M. (2018). Is CRISPR an ethical game changer? Journal of Agricultural and Environmental Ethics, 31, 219-238.

Shriver, A. (2009). Knocking out pain in livestock: Can technology succeed where morality has stalled? Neuroethics, 2, 115-124.

Shriver, A., \& McConnachie, E. (2018). Genetically modifying livestock for improved welfare: A path forward. Journal of Agricultural and Environmental Ethics, 31, 161-180.

Streiffer, R., \& Basl, J. (2011). Ethical Issues in the application of biotechnology to animals in agriculture. In T. Beauchamp \& R. G. Frey (Eds.), The Oxford handbook of animal ethics (pp. 826-854). New York: Oxford University Press

Thompson, P. B. (2008). The opposite of human enhancement: Nanotechnology and the blind chicken problem. Nanoethics, 2, 305-316.

Thorsrud, H. (2015). Aristotle's dichotomous anthropology: What is most human in the Nicomachean ethics? Apeiron, 48, 346-367.

Van Eenennaam, A. L. (2019). Application of genome editing in farm animals: Cattle. Transgenic Research, 28, 93-100.

Veatch, H. B. (1981). Telos and teleology in Aristotelean ethics. In D. J. O'Meara (Ed.), Studies in Aristotle (pp. 279-296). Washington: The Catholic University of America Press.

Wiegel, K. A., \& Shook, G. E. (2018). Genetic selection for mastitis resistance. Veterinary Clinics: Food Animal Practice, 34(2018), 457-472.

Withworth, K. M., Rowland, R. R. R., Ewen, C. L., et al. (2016). Gene-edited pigs are protected from porcine reproductive and respiratory syndrome virus. Nature Biotechnology, 34, 20-22.

Publisher's Note Springer Nature remains neutral with regard to jurisdictional claims in published maps and institutional affiliations. 